\title{
In situ synthesis of nanocrystalline intermetallic layer during surface plastic deformation of zirconium
}

\author{
P. Jiang ${ }^{\text {a }}$, Q. Wei ${ }^{\text {b,* }}$, Y.S. Hong ${ }^{\text {a }}$, J. Lu ${ }^{c}$, X.L. Wu ${ }^{\text {a,* }}$ \\ a State Key Laboratory of Nonlinear Mechanics, Institute of Mechanics, Chinese Academy of Sciences, Beijing 100080, China \\ ${ }^{\mathrm{b}}$ Department of Mechanical Engineering and Engineering Science, University of North Carolina at Charlotte, Charlotte, NC 28223, USA \\ ${ }^{\mathrm{c}}$ Department of Mechanical Engineering, The Hong Kong Polytechnic University, Hung Hom, Kowloon, Hong Kong, China
}

Received 22 March 2007; accepted in revised form 18 June 2007

Available online 10 July 2007

\begin{abstract}
By means of a surface plastic deformation method a nanocrystalline (NC) intermetallic compound was in situ synthesized on the surface layer of bulk zirconium ( $\mathrm{Zr}$ ). Hardened steel shots (composition: 1.0C, $1.5 \mathrm{Cr}$, base Fe in wt.\%) were used to conduct repetitive and multidirectional peening on the surface layer of Zr. The microstructure evolution of the surface layer was investigated by X-ray diffraction and scanning and transmission electron microscopy observations. The NC intermetallic layer of about $25 \mu \mathrm{m}$ thick was observed and confirmed by concentration profiles of $\mathrm{Zr}, \mathrm{Fe}$ and $\mathrm{Cr}$, and was found to consist of the $\mathrm{Fe}_{100-x} \mathrm{Cr}_{x}$ compound with an average grain size of $22 \mathrm{~nm}$. The $\mathrm{NC}$ surface layer exhibited an extremely high average hardness of $10.2 \mathrm{GPa}$. The $\mathrm{Zr}$ base immediately next to the compound/Zr interface has a grain size of $\sim 250 \mathrm{~nm}$, and a hardness of $\sim 3.4 \mathrm{GPa}$. The $\mathrm{Fe}_{100-x} \mathrm{Cr}_{x}$ layer was found to securely adhere to the $\mathrm{Zr}$ base.

(C) 2007 Elsevier B.V. All rights reserved.
\end{abstract}

Keywords: Nanocrystalline; Intermetallic compound; Plastic deformation; Diffusion

\section{Introduction}

The fabrication of nanocrystalline (NC) surface layers on bulk metallic materials has drawn increasing interest because of the novel and exciting mechanical and physical properties such NC surface layers can bring about. Various surface plastic deformation techniques [1-5] have shown the capability of generating $\mathrm{NC}$ microstructures on the surface of metals and alloys. In general, surface nanocrystallization is achieved through successive grain refinement down to the nanometer regime via a number of mechanisms of grain subdivision, including formation of dislocation sub-boundaries and their evolution towards high disorientations [3,6,7], martensitic transformation [8-10] and deformation twinning [8-11]. All these processes can be induced by imposing large plastic strains, sometimes combined with high strain rates, without changing the chemical composition of the material.

\footnotetext{
* Corresponding authors.

E-mail addresses: qwei@uncc.edu (Q.Wei),xlwu@imech.ac.cn (X.L.Wu).
}

On the other hand, surface nanocrystallization may greatly enhance the diffusion kinetics of atomic species. For example, the nitriding temperature of $\mathrm{NC}$ iron can be reduced to $300^{\circ} \mathrm{C}$, at least $200{ }^{\circ} \mathrm{C}$ below the conventional nitriding temperature [12]. The diffusivity of $\mathrm{Cr}$ in NC iron is 7-9 orders of magnitude higher than that in the coarse-grained counterpart and 4-5 orders of magnitude higher than that in the grain boundary of $\alpha-\mathrm{Fe}$ [13]. The mechanically-processed $\mathrm{NC}$ materials indeed exhibit strongly enhanced diffusion compared to the non-mechanically fabricated $\mathrm{NC}$ materials (e.g., by powder metallurgy that produces more equilibrium microstructures than those via. mechanical fabrication), as well as the coarse-grained materials $[14,15]$. The unusual fast diffusion can be ascribed to the presence of deformation-induced nonequilibrium grain boundaries, generation of non-equilibrium excessive vacancies and other defects such as dislocations and twins, and accumulation of lattice strains. As a result, solid-state reactions may occur in the following sequence with the actual extent depending on the amount of plastic strain introduced: the formation of (a) supersaturated solid solution [16], (b) intermetallic compound [17], and (c) amorphous phases [18]. 


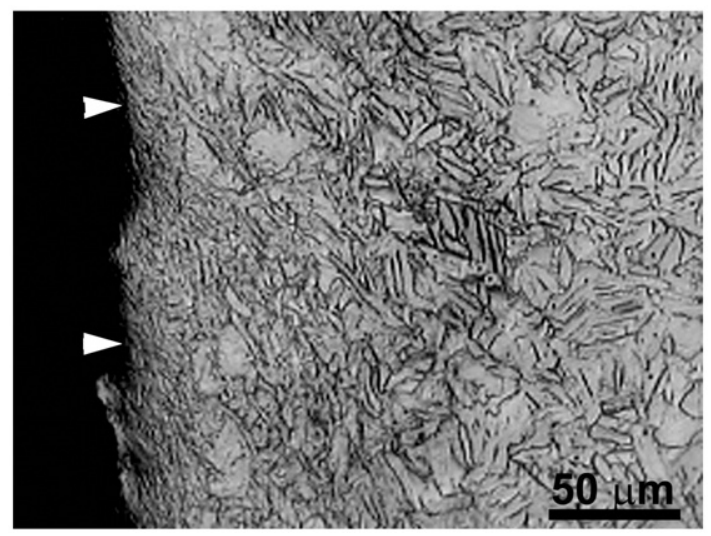

Fig. 1. Optical micrograph of the cross-section of a SMAT specimen. The arrows indicate the treated surface.

Accelerated solid-state diffusion in metals under intensive cold plastic deformation was observed in a wide range of strains and strain rates, as in the case of mechanical alloying (see, e.g., the review [19] and references therein). Therefore, a strategy may be used to generate NC layers with novel phase structures different from the metallic matrix via deformation-induced fast atom diffusion that may accompany the severe plastic deformation (SPD) process.

Intermetallic phases are often lighter, stronger, stiffer, and more corrosion-resistant than the constituent elemental metals, and are therefore particularly suited for high temperature applications. Yet their uses are quite limited at this point because they may suffer from poor roomtemperature ductility and fracture toughness, rendering them difficult to form and vulnerable to fail. These major drawbacks, however, could be effectively circumvented by processing materials with nanostructures [20]. Several methods have been exploited toward this purpose, encompassing rapid self-propagating synthesis and thermal spraying $[21,22]$. The resultant structures are, however, found to be inferior due to the residual porosity and contamination, and poor adhesion of the coating layers to the substrates. Such difficulties have become the obstacles to the structural applications of intermetallic surface layers and coatings in some critical and demanding service conditions. Considering these limitations, we believe that new methodologies should be explored to surmount these obstacles. We envision that the mechanical processes based on SPD are likely to address the problems by the in situ generation of the intermetallic compounds.

The aim of the present study is to produce by SMAT an $\mathrm{NC}$ intermetallic surface layer in a bulk specimen of commercially pure zirconium. The strategy is through introducing highly enhanced diffusion paths during SPD which facilitate an alloying process via deformation-induced diffusion occurring concomitantly during SPD. The NC layer of $\sim 25 \mu \mathrm{m}$ thick consists of the $\mathrm{Fe}_{100-x} \mathrm{Cr}_{x}$ intermetallic phase with an average grain size of $22 \mathrm{~nm}$. We found that the surface layer with an NC microstructure also exhibits an unusually high hardness of $10.2 \mathrm{GPa}$.

\section{Experimental procedure}

The base material used in this study is commercial purity zirconium, which has the vender-certified chemical composition (in wt. \%) of $0.15 \mathrm{Fe}, 0.03 \mathrm{Cr}, 0.007 \mathrm{Ni}, 0.01 \mathrm{Hf}, \mathrm{O}<0.16$, $0.0065 \mathrm{~N}$, and $\mathrm{Zr}$ balance. The bases had a dimension of $5 \times 50 \times 100 \mathrm{~mm}^{3}$. They were mechanically gritted with silicon carbide papers and polished to a mirror finish. Prior to SPD, the bases were vacuum annealed at $950^{\circ} \mathrm{C}$ for $4 \mathrm{~h}$.

SMAT was used to implement in situ production of the NC intermetallic layer. The SMAT technique was detailed elsewhere [1,2,6-8]. In brief, the hardened steel balls were placed at the bottom of a cylinder-shaped vacuum chamber attached to a vibration generator. During the SMAT process, the balls were resonated with the vibrational motions of the system, and they impinged on the surface of the base material. Because of the high vibration frequency of the system, the surface of the base was bombarded repetitively by a large number of balls within a short period of time. As such, the grains in the treated surface layer were effectively refined into the nanoscale regime due to the large imposed strains as well as the high strain rates associated with the SMAT technique [6-8]. Essentially, a strain gradient and a strain rate gradient exist in the surface layer being impacted by the balls, with the peak strain and strain rates expected on the top surface. Even though it is difficult to precisely assess the maximum strains and strain rates associated with SMAT events, recent finite element modeling on shotpeening processes may provide some preliminary insight into this issue. Strain rate in the order of $\sim 10^{5} \mathrm{~s}^{-1}$ was achieved during shot peening as modeled by Meguid et al. [23]. Considering the difference between shot peening and SMAT in terms of impact velocity and dimension of balls [2], the maximum average strain rate achieved during SMAT may be one order of magnitude lower than that of shot peening. The work by Frija et al. showed that the maximum local von Mises equivalent strain associated with one peening event can be as high as 0.15 [24]. Strains and strain rates taper down as we move away from the top surface, and quickly vanish toward the interior of the matrix. Accordingly, the grain size in the base material will also exhibit a gradient $[1,2]$. Hence, one may examine the process of microstructural evolution in the treated layer as a function of strain and strain rates, which may provide

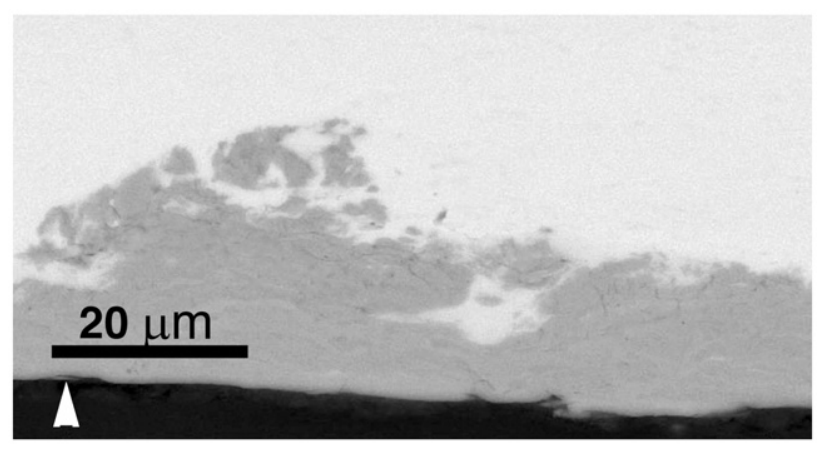

Fig. 2. SEM backscattered electron micrograph of the cross-section of a SMAT specimen. Notice the sharp image contrast between the region close to the top surface (dark contrast) and the Zr base interiors (light contrast). 


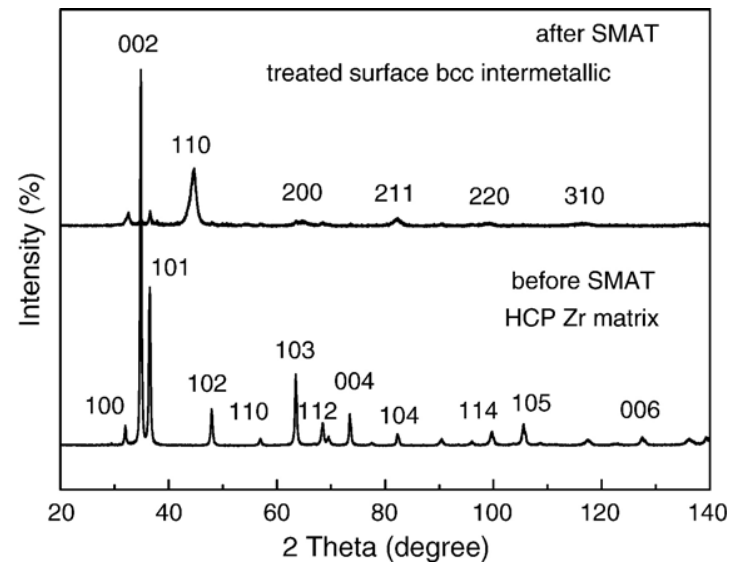

Fig. 3. XRD patterns of the specimen surface prior to and after SMAT. The peaks of the non-treated specimen can be solely indexed by the hop Zr structure. However, the $\mathrm{Zr}$ peaks are all suppressed in the SMAT specimen. Instead, the peaks from the SMAT specimen can be indexed with a bcc structure associated with the $\mathrm{Fe}$ rich $\mathrm{Fe}_{100-x} \mathrm{Cr}_{x}$ intermetallic phase.

abundant information as regard to the various mechanisms responsible for microstructure evolution.

In the present work, the SMAT was performed in vacuum at room temperature for $50 \mathrm{~min}$, at a vibrating frequency of $50 \mathrm{~Hz}$. Hardened steel balls of diameter $8 \mathrm{~mm}$ were used as the bombarding medium, with the following nominal chemical composition (in wt. \%): 1.0 C, 1.5 Cr, base Fe.

Following SMAT, the microstructures were analyzed using transmission electron microscope (TEM, JEM200CX) operated at $200 \mathrm{kV}$. The cross-sectional thin foils for TEM observations were prepared as follows: (1) two pieces (dimension $1 \times 2 \times 5 \mathrm{~mm}^{3}$ ) of the treated layer were cut out and glued face-to-face securely; (2) this was loaded into a die to be pressed and held for $24 \mathrm{~h}$; (3) it was then sliced into thin sheets of about $0.1 \mathrm{~mm}$ thick normal to the treated surface; (4) the sheets were then mechanically thinned down to about $40 \mu \mathrm{m}$ thick followed by Ar ion milling near the bonding-line using a Gatan PIPS with a small incident angle, allowing large, thin and homogeneous electron-transparent areas to be obtained. The phase structures, chemical composition and cross-sectional morphology of the surface layer were also investigated using optical microscopy, X-ray diffraction (XRD, Philips X'Pert PRO with BraggBrentano geometry and $\mathrm{Cu} \mathrm{K} \alpha$ radiation with wavelength $\lambda=1.54 \AA$ ) and scanning electron microscopy (SEM, FEL Sirion400nc) equipped with energy dispersive X-ray (EDX). The cross-sectional hardness profile of the SMAT surface layer was measured using an instrumented nanohardness tester (MTS Nano Indenter ${ }^{\mathrm{XP}}$ ).

\section{Experimental results}

Fig. 1 is an optical micrograph showing the cross-sectional morphology of a surface layer after SMAT. The average grain size of the $\mathrm{Zr}$ matrix is ca. $30 \mu \mathrm{m}$. When approaching the treated top surface indicated by the arrows, the grain boundary contrast disappears gradually, implying a continuous grain refinement starting from the outmost surface, with the refinement diminishing towards the interior of the $\mathrm{Zr}$ base. Fig. 2 is a micrograph from an un-etched cross-section via SEM backscattered electron (BSE) imaging. A thin layer of $\sim 20 \mu \mathrm{m}$ is revealed with distinct dark contrast compared to the $\mathrm{Zr}$ base. This remarkable change in contrast is indicative of the difference in chemical composition between the surface layer and the $\mathrm{Zr}$ base upon SMAT.

Fig. 3 displays XRD patterns taken from the specimen before and after SMAT, respectively. The Miller indices of the reflecting planes corresponding to each peak are given in the figure. Prior to SMAT, XRD gives exclusively the typical peaks associated with the hexagonal closely packed (hcp) structure of $\mathrm{Zr}$ (the lattice parameter of hcp $\mathrm{Zr}$ is $3.231 \AA$ with c/a ratio 1.593 [25]). After SMAT, however, the hcp peaks were suppressed by the appearance of those from a more symmetric lattice structure (with much fewer peaks). Now the XRD peaks can be indexed with a body-centered cubic (bcc) structure, with the lattice parameters in accord with those of the $\alpha$-phase with composition $\mathrm{Fe}_{100-x} \mathrm{Cr}_{x}$ [26]. In other words, the surface phase formed during SMAT is Fe-rich solid solution with a bcc structure. Obvious peak broadening can be observed in the

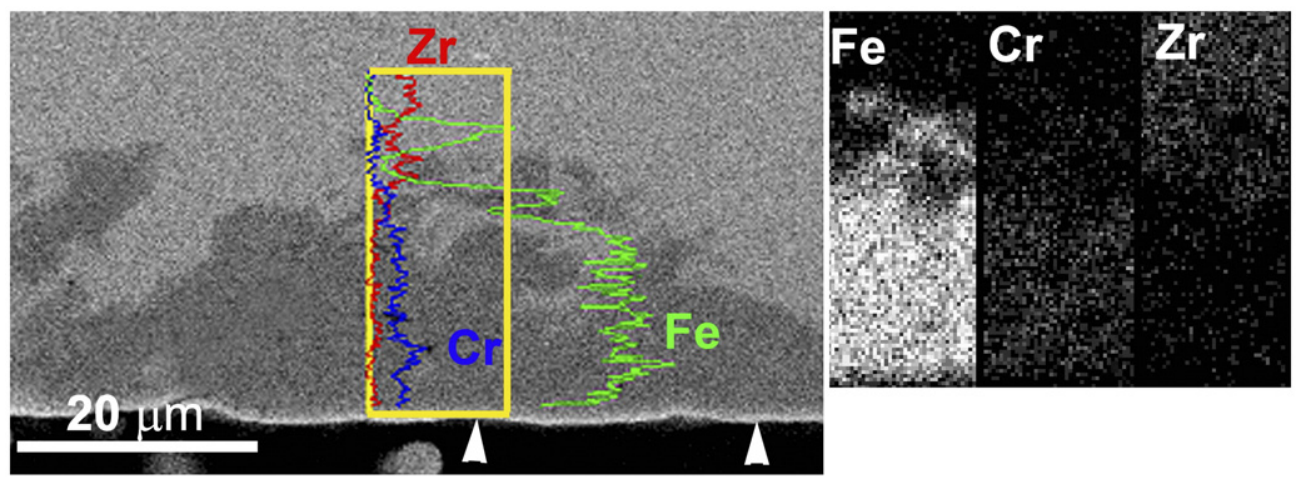

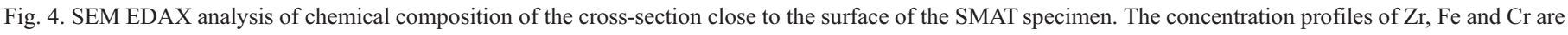

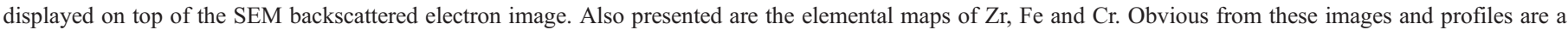

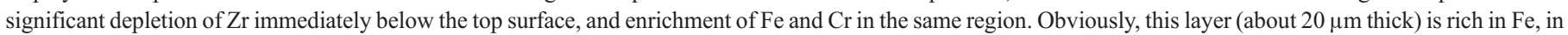
accordance with the XRD results. 


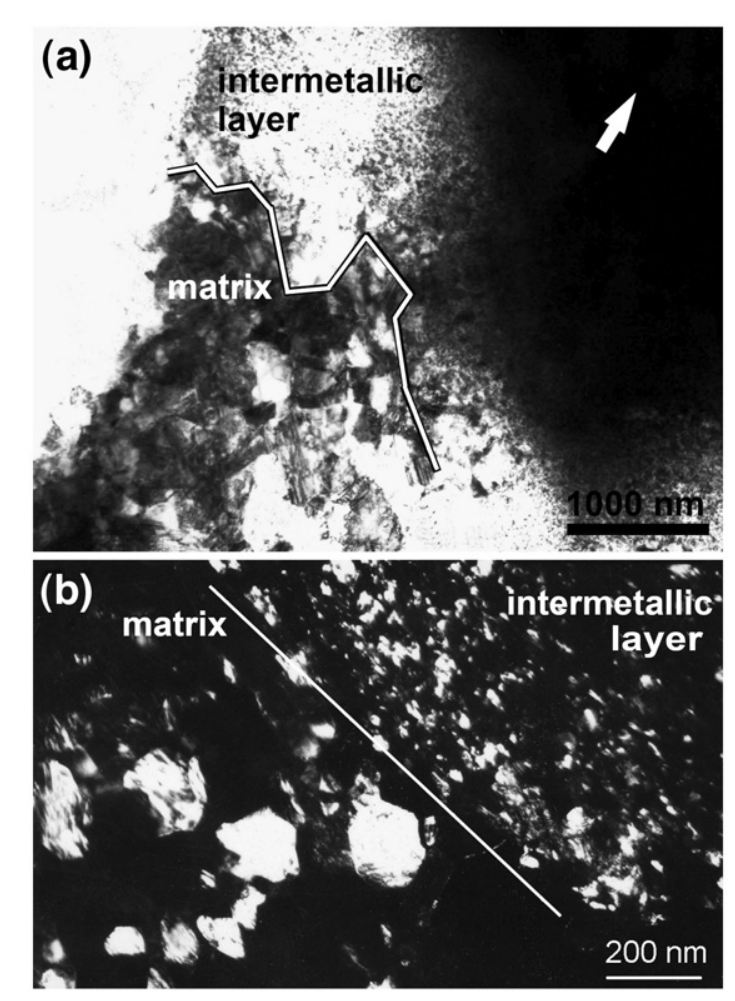

Fig. 5. (a) TEM bright-field cross-sectional image showing the interface between the intermetallic layer and the Zr base; (b) dark-field TEM cross-section image showing an abrupt change in grain size across the interface at about $22 \mu \mathrm{m}$ deep from the top surface.

XRD pattern which is due to the nano-meter crystallites and the large microstrains from SPD of the SMAT treated surface layer.

The chemical composition of the treated layer was probed using an EDX system attached to the SEM. Fig. 4 is an SEM (BSE) micrograph of the SMAT treated cross-section of a specimen. The concentration profiles of $\mathrm{Zr}, \mathrm{Fe}$ and $\mathrm{Cr}$ are also presented along with the SEM backscattered image. Juxtaposed with this image are the elemental maps for $\mathrm{Zr}, \mathrm{Fe}$ and $\mathrm{Cr}$, respectively. The concentration profiles and the elemental maps clearly show a depletion of $\mathrm{Zr}$ and accumulations of both $\mathrm{Cr}$ and Fe in the surface layer $(\sim 20 \mu \mathrm{m}$ deep). They also suggest that this layer is remarkably rich in Fe, in line with the XRD results that an Fe rich bcc intermetallic phase $\left(\mathrm{Fe}_{100-x} \mathrm{Cr}_{x}\right)$ has been produced during the SMAT process. Therefore, an apparent premise will be that $\mathrm{Fe}$ and $\mathrm{Cr}$ from steel balls were forced into the treated surface of $\mathrm{Zr}$ during SMAT by means of some much enhanced diffusion processes.

In order to elucidate the details of the formation of the intermetallic compound during SMAT, the interface between the intermetallic layer and the $\mathrm{Zr}$ base is examined via crosssectional TEM. Fig. 5 (a) is a cross-sectional TEM bright-field image taken close to the interface between the intermetallic layer and the $\mathrm{Zr}$ base, with the interface marked out in the image. It exhibits a zigzag trace, but no crack is found along the interface, implying that the intermetallic layer is securely bonded to the $\mathrm{Zr}$ base. Another interesting observation, as displayed in the dark-field TEM image of Fig. 5 (b), is the presence of extremely fine intermetallic grains. Furthermore,
Fig. 5 (b) suggests an abrupt change in grain size across the interface.

Fig. 6 (a) is a cross-sectional TEM bright-field image taken from the intermetallic layer about $5 \mu \mathrm{m}$ deep from the top surface of the SMAT specimen, revealing the $\mathrm{Fe}_{100-x} \mathrm{Cr}_{x} \mathrm{NC}$ grains. The inset of Fig. 6 (a) is the corresponding selected-area electron diffraction (SAED) pattern showing a set of rings. The rings were indexed with a bcc structure, in line with XRD analysis of Fig. 3. The ring of strongest intensity is $\{110\}$; all

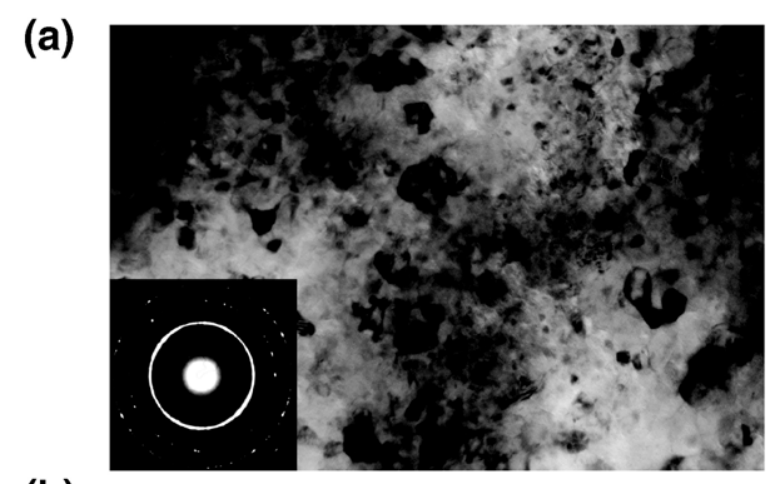

(b)

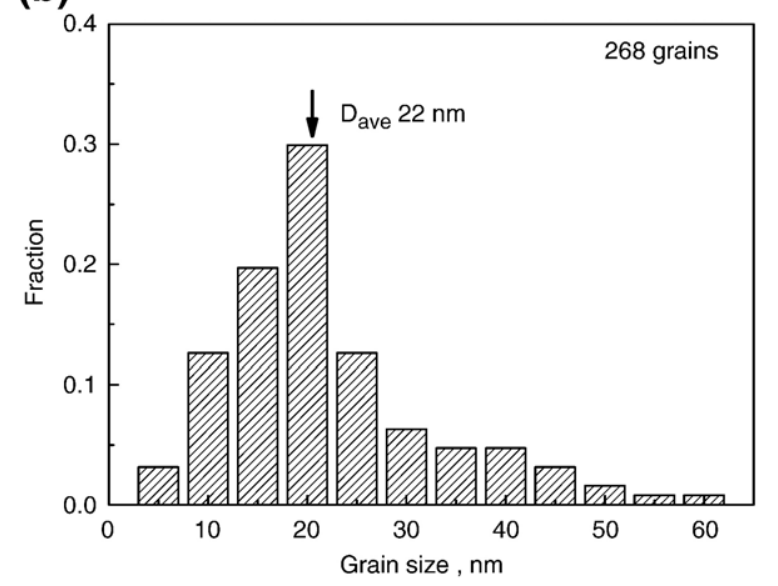

(c)

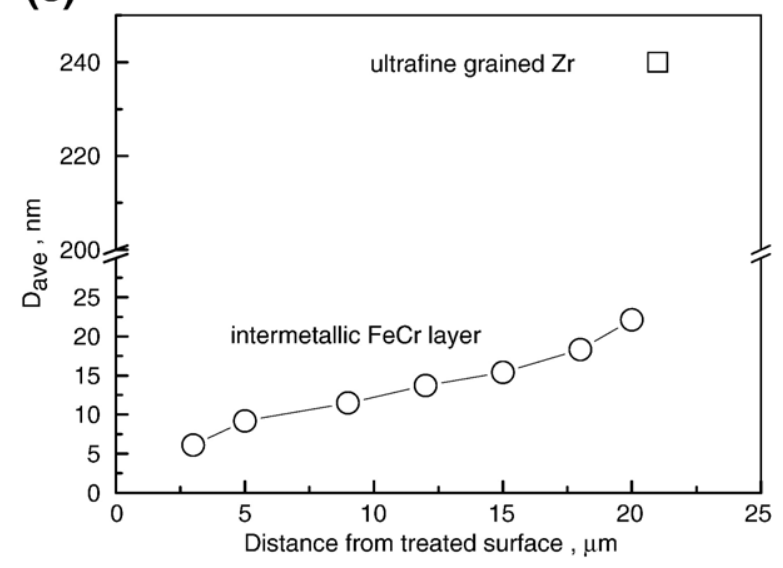

Fig. 6. (a) TEM bright-field image of nanocrystalline $\mathrm{Fe}_{100-x} \mathrm{Cr}_{x}$ compound at about $5 \mu \mathrm{m}$ deep from the top surface of the SMAT specimen. Inset is the corresponding SAED pattern showing rings that can be indexed with the bcc $\mathrm{Fe}_{100-x} \mathrm{Cr}_{x}$ phase. (b) Histogram of grain size distribution of the $\mathrm{Fe}_{100-x} \mathrm{Cr}_{x}$ phase, with the average grain size sitting at $22 \mathrm{~nm}$. (c) Average grain size of the $\mathrm{Fe}_{100-x} \mathrm{Cr}_{x}$ phase as a function of the depth from the top surface. 
other rings, even though continuous, are much weaker. Combined with the XRD results presented in Fig. 3, we see that the integrated intensities of the reflections do not follow standard powder patterns of bcc structures with absolute random orientations. This implies that the $\{110\}$ planes are preferentially oriented for diffraction. Further effort may be needed to investigate the detailed orientations of the nanometer crystallites within the surface layer. Fig. 6 (b) gives the histogram of the grain size distribution of the $\mathrm{Fe}_{100-x} \mathrm{Cr}_{x}$ grains. They have a narrow size distribution ranging from 5 to $60 \mathrm{~nm}$ with an average size of $22 \mathrm{~nm}$. Fig. 6 (c) shows the variation of the mean grain size of the $\mathrm{Fe}_{100-x} \mathrm{Cr}_{x}$ phase as a function of the distance from the top surface of the SMAT specimen. It shows a linear gradient of grain size as one moves away from the top surface of the SMAT specimen.

The microstructure of the $\mathrm{Zr}$ base in the immediate proximity of the interface is also observed. Fig. 7(a) displays a bright-field TEM image of such a region $(\sim 25 \mu \mathrm{m}$ deep from the top surface of the SMAT specimen), showing the equi-axed ultrafine grains (UFGs) of Zr. Their sizes are apparently within the submicron regime, indicative of the significant grain refinement of the $\mathrm{Zr}$ base during SMAT. The grain boundary fringes marked by arrows are visible in many grains. Moreover, a large number of dislocations are observed in numerous grains. Fig. 7 (b) displays one example of the presence of subgrains, dislocation cells and individual dislocations even in such an ultrafine grain. However, accurate measurement of the dislocation densities in both images is extremely difficult.
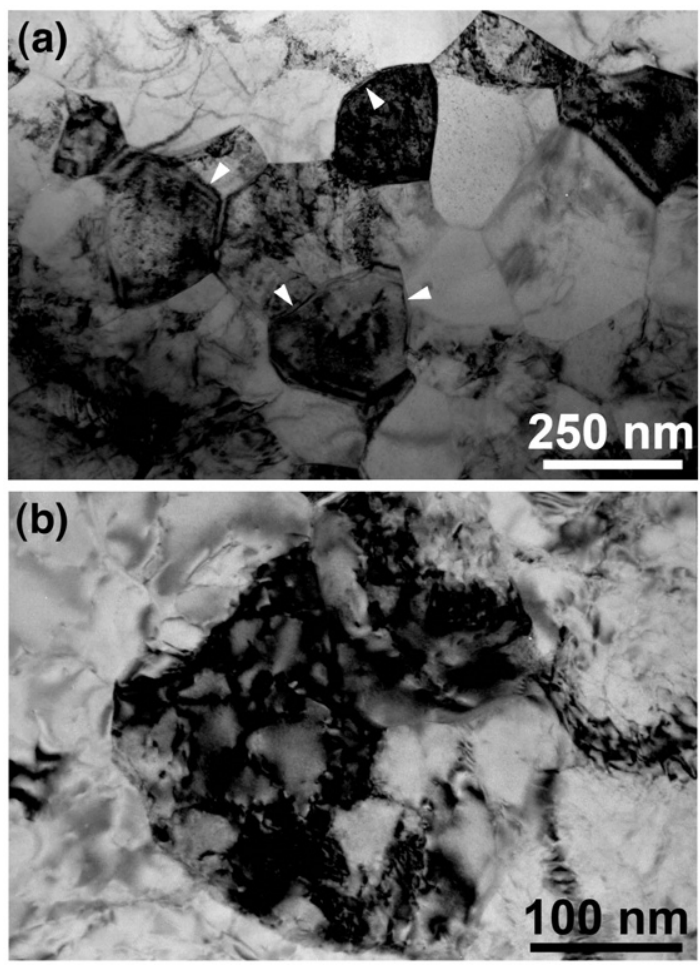

Fig. 7. TEM micrographs of the much refined $\mathrm{Zr}$ grains, taken at locations immediately next to the $\mathrm{Fe}_{100-x} \mathrm{Cr}_{x} / \mathrm{Zr}$ base interface (about $25 \mu \mathrm{m}$ deep from the top surface), showing (a) ultrafine grains and (b) subgrains and dislocations inside one of the ultrafine grains.

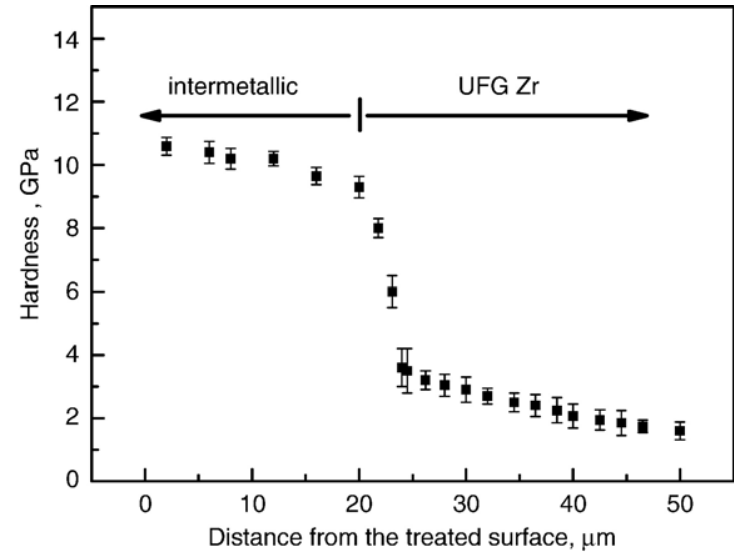

Fig. 8. Hardness profile across the cross-section of a SMAT specimen. Notice the sharp change in hardness at the $\mathrm{Fe}_{100-x} \mathrm{Cr}_{x} / \mathrm{Zr}$ base interface. This is consistent with optical microscopy, SEM, chemical analyses and TEM observations presented in preceding figures.

The cross-sectional hardness profile across the interface of a SMAT specimen is plotted in Fig. 8. The hardness was measured with an instrumented nanoindenter. Each data point in the plot is the average of at least 8 indentations which were performed at a constant loading rate to an indentation depth of $2 \mu \mathrm{m}$. The average hardness of the $\mathrm{Fe}_{100-x} \mathrm{Cr}_{x}$ intermetallic layer is $\sim 10.2 \mathrm{GPa}$, which is about 3 times higher than that of the UFG $\mathrm{Zr}$ base immediately adjacent to the interface. We believe that both the intrinsic high hardness and the $\mathrm{NC}$ grains of the $\mathrm{Fe}_{100-x} \mathrm{Cr}_{x}$ intermetallic layer contribute to the observed high hardness of the surface layer of the SMAT specimen.

\section{Discussion}

The continuous grain refinement during SMAT takes place as a result of the accommodation of the imposed plastic strains $[1,2]$. At the interface between the $\mathrm{Fe}_{100-x} \mathrm{Cr}_{x}$ intermetallic layer and the $\mathrm{Zr}$ base (Figs. 5 and 7), we found the formation of the UFG Zr grains with an average grain size of $\sim 250 \mathrm{~nm}$. A high dislocation density is also observed within these grains (Fig. 7), suggesting dislocation activities are the dominating deformation mechanism in such a grain size regime. Such phenomena have been discussed by other workers [11], and will not be dealt with in the present paper.

Atomic diffusion in materials may occur by the mono-vacancy mechanism. Excess vacancies can be produced by plastic deformation which causes an increase in the atomic jump rate which in turn increases the diffusivity of the species in the material.

The existence of excess vacancies is a result of the competition of a generation mechanism (for example, via. intersections of screw dislocations, jog climbing, etc.) and an annihilation mechanism through migration of vacancies to sinks [27]. The formation process may be governed by the nonconservative motion (climbing) of jogs or intersections of screw dislocations under a certain strain rate [27]. The jogs are created by the moving dislocations intersecting and cutting the dislocation forests [28]. Meanwhile, compared to the grain interiors severe lattice distortion and high defect density (e.g., 
dislocations) exist in the vicinity of grain boundaries (GBs). Thus, the vacancy generation in the GB regions should be larger than in the grain interiors [29].

Many workers have proved that vacancy concentrations in metals and alloys increase tremendously upon plastic deformation, particularly SPD. Detemple et al. observed enhanced atomic diffusion under plastic deformation in aluminum using nuclear spin relaxation technique [30]. Using a combination of XRD line profile analysis, electrical resistometry and calorimetry, Schafler et al. [31] measured the vacancy concentrations in deformed microstructures which are usually within the submicron grain size regime. They found that the vacancy concentration is of the order of $\sim 10^{-4}$, which is very close to that near the melting point of the material. Non-equilibrium, excess vacancies generated within the top-surface layer of the $\mathrm{Zr}$ base may substantially expedite the diffusion process of both $\mathrm{Fe}$ and $\mathrm{Cr}$ into the $\mathrm{Zr}$ base. The excess vacancy concentration will be proportional to both the imposed strain rate and the dislocation density [32]. In the course of diffusion, vacancies and interstitials may recombine, or they may interact with edge dislocations which can act as volume-distributed sinks for nonequilibrium defects. Such processes serve as the vacancy annihilation mechanisms. It may also be pointed out that recent work by Soer et al.[33] suggests that in the case of $\mathrm{Al}$, above $500 \mathrm{~K}$, plasticity induced excess vacancies should not play a significant role in the climb and diffusional processes. Our analysis presented later on indicates that local adiabatic temperature rise during SMAT is within $50-100 \mathrm{~K}$, we therefore believe that deformation-induced excess vacancies should still contribute considerably to the enhanced diffusivity.

SMAT will rapidly refine the grain size of the base material into nanometer regimes (grain size below $10 \mathrm{~nm}$ is frequently reported in the literature [2]). With the formation of the NC grains, the diffusion kinetics will probably be further enhanced, and eventually lead to the formation of solid solutions as described previously. The intermetallic phase is of nanometer sizes, as can be seen from Figs. 5 and 6. This will render dislocation nucleation much more difficult within these $\mathrm{Fe}_{100-x} \mathrm{Cr}_{x}$ grains. It is noted that the very fine $\mathrm{NC}$ grains contain a considerable volume fraction of triple junctions (TJs) as well as GBs [34]. Because TJs have a loosely bonded structure and therefore a large excess volume (or free volume) compared to GBs, the TJs can serve as fast diffusion paths $[35,36]$, in much the similar way to those GBs [37]. Furthermore, recently Schuh et al. have examined the diffusion kinetics of nanocrystalline materials and conclude that if grain size is below $10 \mathrm{~nm}$, diffusion is dominated by TJs [38,39]. Moreover, the SPD generated GBs are in a high-energy, nonequilibrium state. The energy stored in such GBs may either facilitate diffusion through lowering defect formation energy or serving as driving force for the formation of a solid solution $[16,37]$. It is worthy of further pointing out that the large stress from the continual steel ball impingement may also serve to increase the diffusion driving force, and thus further enhance the diffusion kinetics of the atomic species. The rapid atomic diffusion leads to quick homogenization of $\mathrm{Fe}$ and $\mathrm{Cr}$ distributions and to continuous formation of the $\mathrm{Fe}_{100-} \mathrm{Cr}_{x}$ intermetallic phase within the surface layer during SMAT.
High speed bombardment of the surface by the hardened steel balls results in local adiabatic heating. Several reports have evaluated the adiabatic temperature rise to be from 10 to $120 \mathrm{~K}$ during mechanical attrition (MA), with the specific value depending upon the milling type and condition [19]. Using the strains from finite element analysis (von Mises strain ca. 0.15, [24]), and the stress level during SMAT, and the Taylor-Quinney equation [40], i.e., $\Delta T=\sigma \varepsilon / \rho C_{\mathrm{P}}$, where $\rho$ is the density and $C_{\mathrm{P}}$ is the specific heat of the material, which are $6.5 \mathrm{~g} / \mathrm{cc}$ and $25.4 \mathrm{~J} / \mathrm{mol} \mathrm{K}$ for $\mathrm{Zr}$, respectively. This equation assumes that the material under consideration is elastic-perfectly plastic, and no heat has been dissipated away, namely, the impingement is perfectly adiabatic due to the extremely high strain rate. The local adiabatic temperature rise can be estimated to be around $50-100 \mathrm{~K}$ [2]. Since the atomic diffusion coefficient is an exponential function of temperature, this local adiabatic heating may significantly enhance the diffusion processes during SMAT.

The formation of intermetallic phases during MA of ductile alloy systems with a negative heat of mixing between the constituent elements has been explained by an inter-diffusion reaction between the constituent elements $[19,41]$. In the present study, true alloying on the atomic level is achieved through two diffusion mechanisms operating concurrently within two separate grain size regimes, i.e. the submicron and nanometer regimes.

This work has demonstrated a new technical route that can be employed for in situ alloying on the surface of metallic materials. This route allows the elimination of the various lengthy stages involved in traditional syntheses of intermetallic materials. During the SMAT process the highly energetic hardened steel balls impinge continually on the surface of the base material. As a result of the high impact velocities and frequencies of impinging events, high local strain rate, strain, stress and considerable local adiabatic heating work collectively to greatly enhance diffusion, and thus to accelerate the alloying processes. This is quite similar to what happens during mechanical alloying. Consequently, the formation of a wide spectrum of stable and meta-stable compounds becomes possible. We believe that this provides a genuine avenue for the syntheses of novel materials and for the applications of nanoengineering, with the proviso that judicious selection of the composition of the target materials, as well as other conditions for the processes, can be made.

\section{Summary}

A nanocrystalline layer consisting of the $\mathrm{Fe}_{100-x} \mathrm{Cr}_{x}$ intermetallic phase was in situ produced during surface SPD of bulk $\mathrm{Zr}$. Repetitive peening of the $\mathrm{Zr}$ base by hardened steel balls results in fast move of $\mathrm{Fe}$ and $\mathrm{Cr}$ atoms into the $\mathrm{Zr}$ base by means of deformation-enhanced diffusion, and leads to the formation of the intermetallic compound.

The $\mathrm{NC} \mathrm{Fe}_{100-x} \mathrm{Cr}_{x}$ intermetallic layer is $\sim 20 \mu \mathrm{m}$ thick, with an average grain size of $\sim 22 \mathrm{~nm}$ and has an average hardness of 10.2 GPa. The hardness is about 3 times higher than the hardest part of the $\mathrm{Zr}$ base. The grain size of the $\mathrm{Zr}$ base immediately next to the $\mathrm{Fe}_{100-x} \mathrm{Cr}_{x} / \mathrm{Zr}$ interface is about $250 \mathrm{~nm}$. 
Based on the present work, the surface deformation technique appears to be a suitable avenue for room-temperature syntheses of intermetallic surface layers on some bulk base materials. It is advantageous over the conventional thermal processes in that it helps to overcome the stumbling blocks associated with the latter, such as residual porosity, contamination, and poor adhesion to the base.

\section{Acknowledgements}

The research was supported by NSF of China under Grant Nos. 50471086, 50571110, and 10472117, 973 Program of China under Grant No 2004CB619305, the Chinese Academy of Sciences under Grant No KJCX2-YW-M04 and Innovation Program and National Center for Nanoscience and Technology of China.

\section{References}

[1] K. Lu, J. Lu, J. Mater. Sci. Technol. 15 (1999) 193.

[2] K. Lu, J. Lu, Mater. Sci. Eng., A 375-77 (2004) 38.

[3] D.A. Hughes, N. Hansen, Phys. Rev. Lett. 87 (2001) 135503-1-3.

[4] Dai, J. Villegas, L. Shaw, Scr. Mater. 52 (2005) 259.

[5] Todaka, M. Umemoto, K. Tsuchiya, Mater. Trans. 45 (2004) 376.

[6] X. Wu, N. Tao, Y. Hong, B. Xu, J. Lu, K. Lu, Acta Mater. 50 (2002) 2075.

[7] N.R. Tao, Z.B. Wang, W.P. Tong, M.L. Sui, J. Lu, K. Lu, Acta Mater. 50 (2002) 4603

[8] H.W. Zhang, Z.K. Hei, G. Liu, J. Lu, K. Lu, Acta Mater. 51 (2003) 1871

[9] X. Wu, N. Tao, Y. Hong, G. Liu, B. Xu, J. Lu, K. Lu, Acta Mater. 53 (2005) 681.

[10] X. Wu, N. Tao, Y. Hong, J. Lu, K. Lu, Scr. Mater. 53 (2005) 547.

[11] N.R. Tao, X.L. Wu, M.L. Sui, J. Lu, K. Lu, J. Mater. Res. 19 (2004) 1623.

[12] W.P. Tong, N.R. Tao, Z.B. Wang, J. Lu, K. Lu, Science 299 (2003) 686.

[13] Z.B. Wang, N.R. Tao, W.P. Tang, J. Lu, K. Lu, Acta Mater. 51 (2003) 4319.

[14] M.D. Baro, Yu-R. Kolobov, I.A. Ovid'ko, H-E. Schaefer, B.B. Straumal, R.Z. Valiev, I.V. Alexandrov, M. Ivanov, K. Reimann, A.B. Reizis, S. Surinach, A.P. Zhilyaev, Rev. Adv. Mater. Sci. 2 (2001) 43.
[15] M. Yu Gutkin, I.A. Ovid'ko, C.S. Pande, Rev. Adv. Mater. Sci. 2 (2001) 80.

[16] Y. Ivanisenko, W. Lojkowski, R.Z. Valiev, H.-J. Fecht, Acta Mater. 51 (2003) 5555.

[17] A.V. Korznikov, O. Dimitrov, G.F. Korznikova, J.-P. Dallas, A. Quivy, R.Z. Valiev, NanoStruct Mater. 11 (1999) 17.

[18] X. Sauvage, F. Wetscher, P. Pareige, Acta Mater. 53 (2005) 2127.

[19] C. Suryanarayana, Prog. Mater. Sci. 46 (2001) 1.

[20] C.C. Koch, D.G. Morris, K. Lu, A. Inoue, MRS Bull. 24 (1999) 54.

[21] J.A. Hearley, J.A. Little, A.J. Sturgeon, Surf. Coat. Technol. 123 (2000) 210.

[22] T. Grosdidier, A. Tidu, H.L. Liao, Scr. Mater. 44 (2001) 387.

[23] S.A. Meguid, G. Shagal, J.C. Stranart, Inter. J. Impact Eng. 27 (2002) 119.

[24] M. Frija, T. Hassine, R. Fathallah, C. Bouraoui, A. Dogui, Mater. Sci. Eng., A 426 (2006) 173.

[25] J.W. Edington, Practical Electron Microscopy in Materials Science, Van Nostrand Reinhold Comp., 1976

[26] A.A. Levin, D.C. Meyer, A. Gorbunov, A. Mensch, W. Pompe, P. Paufler, J. Alloys Compnds. 360 (2003) 107.

[27] K.L. Murty, F.A. Mohammed, J.E. Dorn, Scr. Metall. 5 (1971) 1087.

[28] C.G. Lenasson, Scr. Metall. 6 (1972) 1125.

[29] T. Ungár, Mater. Sci. Forum 503-504 (2006) 133.

[30] K. Detemple, O. Kanert, J.T.M. Dehosson, K.L. Murty, Phys. Rev., B 52 (1995) 125.

[31] E. Schafler, G. Steiner, E. Korznikova, M. Kerber, M.J. Zehetbauer, Mater. Sci. Eng. A. 410-411 (2005) 169.

[32] K.L. Murty, K. Detemple, O. Kanert, J.T.M. Dehosson, Metal. Mater. Trans. A 29 (1998) 153.

[33] W.A. Soer, A.R. Chezan, J.T.M. Dehosson, Acta Mater. 54 (2006) 3827.

[34] G. Palumbo, S.J. Thorpe, K.T. Aust, Scr. Metall. Mater. 24 (1990) 1347.

[35] H.T. Wang, W. Yang, A.H.W. Ngan, Scr. Mater. 52 (2005) 69.

[36] H-E. Schaefer, K. Reimann, W. Straub, F. Phillipp, H. Tanimoto, U. Brossmann, R. Wurschum, Mater. Sci. Eng., A 286 (2000) 24.

[37] A.A. Nazarov, A.E. Romanov, R.Z. Valiev, Acta Metall. Mater. 41 (1993) 1033.

[38] Y. Chen, C.A. Schuh, J. Appl. Phys. 101 (2007) 063524.

[39] Y. Chen, C.A. Schuh, Scr. Mater. 57 (2007) 253.

[40] G.I. Taylor, H. Quinney, Proc. Royal. Soc. London A. 143 (1934) 307.

[41] C.C. Koch, J.D. Whittenberger, Intermetallics 4 (1996) 339. 